\title{
Solute and Volume Dosing during Kidney Replacement Therapy in Critically Ill Patients with Acute Kidney Injury
}

\author{
Raghavan Murugan
}

\begin{abstract}
Among critically ill patients with severe acute kidney injury either continuous kidney replacement therapy (CKRT) or intermittent hemodialysis (IHD) can be performed to provide optimal solute and volume control. The modality of KRT should be chosen based on the needs of the patient, hemodynamic status, clinician expertise, and resource available under a particular setting and consideration of costs. Evidence from highquality randomized trials suggests that an effluent flow rate of $25 \mathrm{~mL} / \mathrm{kg} /$ hour per day using CKRT and $K t / V$ of 1.3 per session of IHD provide optimal solute control. For volume dosing, the net ultrafiltration $\left(\mathrm{UF}_{\mathrm{NET}}\right)$ rate should be prescribed based on patient body weight in milliliters per kilogram per hour, with close monitoring of patient hemodynamics and fluid balance. Emerging evidence from observational studies suggests a "J"-shaped association between $\mathrm{UF}_{\mathrm{NET}}$ rate and outcomes with both faster and slower UF ${ }_{\mathrm{NET}}$ rates being associated with increased

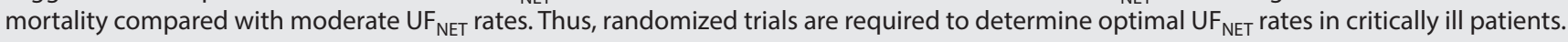
Keywords: Dosing, Kidney replacement therapy, Solute control, Volume control.

Indian Journal of Critical Care Medicine (2020): 10.5005/jp-journals-10071-23391
\end{abstract}

\section{INTRODUCTION}

Kidney replacement therapy (KRT) is frequently used to treat critically ill patients with acute kidney injury (AKI), who have lifethreatening derangements in acid-base balance, electrolytes, and fluid overload. ${ }^{1}$ In a critically ill patient, continuous kidney replacement therapy (CKRT), intermittent hemodialysis (IHD), and hybrid therapies such as prolonged intermittent KRT (PIKRT) can be used for solute, electrolyte, and volume dosing.

For hemodynamically unstable patients who require ongoing, large-volume fluid administration, multiple intravenous (IV) medications, total parenteral nutrition, CKRT is a useful modality for solute, electrolyte, and volume control. Whereas IHD including various forms of PIKRT are used among patients who are hemodynamically stable. Randomized trials have not shown the superiority of one modality of KRT over another and both modalities should be used as complementary therapies, depending upon the needs of the patient.

Dosing of KRT is mostly based on the clearance of urea since urea is considered a surrogate for low-molecular-weight uremic toxins. ${ }^{2}$ Dose of IHD is frequently quantified based on fractional urea clearance per treatment, which is expressed as $K t / V$. The $K t / V$ is a measure of the dialysis dose given in a single treatment, where $K$ is the dialyzer urea clearance, $t$ is the total treatment time, and $V$ is the total volume of distribution of urea in the body. The $K t / V$ is based on urea kinetic models that have been extensively validated in patients with end-stage kidney disease. Despite limitations for use in critically ill patients, $K t / V$ have been satisfactorily applied for dose quantification for acute dialysis.

Solute clearance during CKRT can be calculated as the ratio of the solute concentration in the effluent fluid and the plasma multiplied by the rate of effluent flow. Although the mechanism of solute transfer varies with convective as opposed to diffusive modalities, under usual conditions the concentration ratio between effluent flow and blood for urea and other lowmolecular-weight solutes is close to unity. Thus, small solute clearance is approximately equal to effluent flow, allowing the
Department of Critical Care Medicine, Center for Critical Care Nephrology, CRISMA University of Pittsburgh School of Medicine, Pittsburgh, Pennsylvania, USA

Corresponding Author: Raghavan Murugan, Department of Critical Care Medicine, Center for Critical Care Nephrology, CRISMA University of Pittsburgh School of Medicine, Pittsburgh, Pennsylvania, USA, Phone: +1-412-383-4201, e-mail: muruganr@upmc.edu

How to cite this article: Murugan R. Solute and Volume Dosing during Kidney Replacement Therapy in Critically III Patients with Acute Kidney Injury. Indian J Crit Care Med 2020;24(Suppl 3):S107-S111.

Source of support: National Institute of Diabetes and Digestive and Kidney Disease grant (5R01DK106256)

Conflict of interest: $\mathrm{Dr}$ Murugan reported receiving grants and personal fees from La Jolla Inc; grants from Bioporto, Inc, and the National Institute of Diabetes and Digestive and Kidney Diseases; and personal fees from Beckman Coulter and AM Pharma, Inc, outside the submitted work

dose of CKRT to be expressed as the effluent volume per unit of time normalized to body weight.

\section{Dosing Using CKRT}

Because CKRT is a continuous therapy, the net solute removal over $24-48$ hours is higher than that with IHD. Among critically ill patients with acute brain injury and AKI who are at risk of or have cerebral edema, CKRT is preferred over IHD because IHD is likely to increase intracranial pressure due to rapid removal of solutes resulting in a shift of water into the intracellular space, potentiating cerebral edema.

For patients on any form of CKRT, an effluent flow rate of approximately $25 \mathrm{~mL} / \mathrm{kg} /$ hour is recommended per day in order to achieve a minimum effluent dose of $20 \mathrm{~mL} / \mathrm{kg} /$ hour over a 24-hour period to account for interruptions in CKRT and downtime (Table 1). ${ }^{1}$ This recommendation is based on several high-quality 
Table 1: Clinical trials evaluating solute dosing in critically ill patients with acute kidney injury

\begin{tabular}{|c|c|c|c|c|c|c|}
\hline Author & Study design & No. of patients & KRT modality & Prescribed dose & $\begin{array}{l}\text { Day of mortality } \\
\text { assessment }\end{array}$ & $\begin{array}{l}\text { Mortality: lower vs } \\
\text { higher dose }\end{array}$ \\
\hline Ronco et al. & Single center, RCT & 425 & CVVH & $\begin{array}{l}\text { Effluent flow rate: } 20 \mathrm{~mL} / \mathrm{kg} / \\
\text { hour vs } 35 \mathrm{~mL} / \mathrm{kg} / \text { hour vs } 45 \\
\mathrm{~mL} / \mathrm{kg} / \text { hour }\end{array}$ & 15 & $59 \%$ vs $42.5 \%$ \\
\hline Bouman et al. & Two center, RCT & 106 & $\mathrm{CVVH}$ & $\begin{array}{l}\text { Effluent flow rate: } 19 \mathrm{~mL} / \mathrm{kg} / \\
\text { hour vs } 48 \mathrm{~mL} / \mathrm{kg} / \mathrm{hour}\end{array}$ & 28 & $28.1 \%$ vs $25.7 \%$ \\
\hline Saudan et al. & Single center, RCT & 206 & $\begin{array}{l}\text { CVVH/ } \\
\text { CVVHDF }\end{array}$ & $\begin{array}{l}\text { Effluent flow rate: CVVH - } \\
25 \mathrm{~mL} / \mathrm{kg} / \text { hour; CVVHDF - } \\
42 \mathrm{~mL} / \mathrm{kg} / \text { hour }\end{array}$ & 90 & $61 \%$ vs $41 \%$ \\
\hline Tolwani et al. & Single center, RCT & 200 & CVVHDF & $\begin{array}{l}\text { Effluent flow rate: } 20 \mathrm{~mL} / \mathrm{kg} / \\
\text { hour vs } 35 \mathrm{~mL} / \mathrm{kg} / \mathrm{hour}\end{array}$ & 30 & $44 \%$ vs $51 \%$ \\
\hline Bellomo et al. & Multicenter, RCT & 1,508 & CVVHDF & $\begin{array}{l}\text { Effluent volume: } 25 \mathrm{~mL} / \mathrm{kg} \mathrm{h} \\
\text { vs } 40 \mathrm{~mL} / \mathrm{kg} / \mathrm{hour}\end{array}$ & 90 & $44.7 \%$ vs $44.7 \%$ \\
\hline Schiffl et al. & $\begin{array}{l}\text { Single center, } \\
\text { alternating design }\end{array}$ & 160 & IHD & $\begin{array}{l}K t / V_{\text {urea }} \text { and frequency of IHD: } \\
K t / V_{\text {urea }} \text { of } 1.2 \text { per IHD every } \\
\text { other day vs daily }\end{array}$ & 14 & $46 \%$ vs $28 \%$ \\
\hline $\begin{array}{l}\text { Faulhaber- } \\
\text { Walter et al. }\end{array}$ & Multicenter, RCT & 156 & $\mathrm{ED}$ & $\begin{array}{l}\text { Plasma urea level } \\
120-150 \mathrm{mg} / \mathrm{dL} \text { vs }<90 \mathrm{mg} / \mathrm{dL}\end{array}$ & 14 & $29.3 \%$ vs $29.6 \%$ \\
\hline Palevsky et al. & Multicenter, RCT & 1,125 & $\begin{array}{l}\text { IHD, SLED, } \\
\text { CVVHDF }\end{array}$ & $\begin{array}{l}\mathrm{Kt} / \mathrm{V}_{\text {urea }} \text { and effluent volume: } \\
\mathrm{Kt} / \mathrm{V}_{\text {urea }} \text { of } 1.3 \text { in IHD and } \\
\mathrm{SLED}-3 \text { vs } 6 \text { times/week; } \\
\text { effluent volume, } 20 \mathrm{~mL} / \mathrm{kg} / \\
\text { hour vs } 35 \mathrm{~mL} / \mathrm{kg} / \mathrm{hour}\end{array}$ & 60 & $51.5 \%$ vs $53.6 \%$ \\
\hline
\end{tabular}

KRT, kidney replacement therapy; CVVH, continuous venovenous hemofiltration; CVVHDF, continuous venovenous hemodiafiltration; ED, extended dialysis; SLED, sustained low-efficiency dialysis; IHD, intermittent hemodialysis; RCT, randomized controlled trial

randomized trials. ${ }^{3,4}$ Observational studies have suggested that the actual delivered effluent volume during CKRT is substantially less than the prescribed dose. ${ }^{5,6}$ Therefore, the prescribed dose must exceed the desired delivered dose by a factor of approximately $20-25 \%$ to adjust for interruptions in study therapy.

For patients who have severe metabolic derangements such as hyperkalemia or metabolic acidosis that require more urgent correction over 24-36 hours, we recommend a higher starting dose with an effluent flow rate of $>40 \mathrm{~mL} / \mathrm{kg} / \mathrm{hour}$ up to $70 \mathrm{~mL} / \mathrm{kg} /$ hour until acidosis is partly corrected. ${ }^{7}$ However, once the severe metabolic derangements are improved, the prescribed dose must be decreased to approximately $25 \mathrm{~mL} /$ $\mathrm{kg} /$ hour. Randomized clinical trials have not shown benefit of higher dose ( $>35 \mathrm{~mL} / \mathrm{kg} /$ hour) compared with the standard dose of $20-25 \mathrm{~mL} / \mathrm{kg} / \mathrm{hour}$. $^{3,4}$ In addition, higher doses, particularly if prolonged, may lead to protein malnutrition, severe deficiency of many vitamins and micronutrients, inadequate antimicrobial drug levels, and hypotensive episodes.

We suggest using continuous venovenous hemodialysis (CVVHD) or continuous venovenous hemodiafiltration (CVVHDF), rather than continuous venovenous hemofiltration (CVVH) because diffusive therapies are able to deliver a higher dose without increasing the filtration fraction. The filtration fraction is the fraction of plasma water that is removed from blood during ultrafiltration (UF). We suggest maintaining a filtration fraction $<20 \%$ as higher fractions are associated with increased circuit clotting due to hemoconcentration and blood protein-membrane interactions within the hemofilter. A relatively low filtration fraction can be maintained by (a) keeping the UF flow rate low, (b) increasing the blood flow rate, (c) providing catheter function that can support higher flows, (d) using prefilter replacement fluid in $\mathrm{CVVH}$ or CVVHDF, and (e) switching from CVVH to CVVHD or CVVHDF.
It is important to note that although the use of prefilter replacement fluid in CVVH or CVVHDF will reduce solute clearance by $15-20 \%$. Precise quantification of small solute clearance during CKRT may be achieved by simultaneous measurement of urea in effluent fluid and blood [i.e., effluent fluid urea nitrogen (FUN)/ blood urea nitrogen (BUN) ratio]. Meta-analysis of randomized trials that compared hemofiltration with hemodialysis found no difference in survival or dialysis dependence between the two modalities. ${ }^{8}$

\section{Blood Flow Rate}

We suggest maintaining a blood flow rate of $200 \mathrm{~mL} /$ minute in patients who are on anticoagulation. However, a higher blood flow rate (200-300 $\mathrm{mL} / \mathrm{minute}$ ) is required if anticoagulation is not used in order to maintain catheter patency and circuit life. Low blood flow rates $(<100-150 \mathrm{~mL} /$ minute) can increase hemofilter and circuit failures due to the stasis of blood and an increased filtration fraction since the filtration fraction is inversely proportional to the blood flow. The blood flow rate does not affect hemodynamic stability, since the volume of blood in the circuit at any one time does not change as the blood flow rate changes. Blood flow rates greater than $300 \mathrm{~mL} /$ minute may decrease the hemofilter life span.

\section{Replacement Fluids and Dialysate}

We suggest not to customize the replacement solutions in order to reduce the risks associated with compounding. Multiple commercial replacement solutions are available, with variable concentrations of electrolytes and glucose. Initially, we monitor the electrolytes and acid-base status every $6-12$ hours. If the patient remains stable with minimal changes in electrolytes at 24-48 hours, measurements of electrolytes can be decreased to every 12-24 hours. 


\section{Sodium}

The sodium concentration in replacement solutions ranges from $130-140 \mathrm{mEq} / \mathrm{L}$. For most patients, the sodium concentration should be physiologic (i.e., 135-140 mEq/L). A lower sodium (i.e., $130 \mathrm{mEq} / \mathrm{L}$ ) may be used for patients receiving citrate anticoagulation in order to prevent hypernatremia since the infused citrate solution may be hypertonic.

\section{Potassium}

The potassium concentration ranges from 0 to $4 \mathrm{mEq} / \mathrm{L}$. We use a potassium concentration of $4 \mathrm{mEq} / \mathrm{L}$ for all patients except those with severe hyperkalemia. Either a 0 or $2 \mathrm{mEq}$ potassium solution may be used to treat severe hyperkalemia, depending on which solution is available. For patients on CVVHDF, a $2 \mathrm{mEq} \mathrm{K}$ solution may be generated by using both a $4 \mathrm{~K}$ solution and $0 \mathrm{~K}$ solution delivered at the same rate. However, we emphasize that IHD rather than CKRT is indicated for the treatment of severe hyperkalemia even if the patient requires vasopressors, because even with the highest effluent rates possible with the CKRT, bulk potassium removal is much more efficient with standard IHD.

\section{Bicarbonate}

We suggest using bicarbonate- rather than lactate-based solutions. Serum lactate levels are often higher when lactate-based solutions are used, particularly among patients with liver failure, and may confuse the clinical interpretation of blood lactate levels. Standard solutions have a bicarbonate concentration ranging from 22 to 35 $\mathrm{mEq} / \mathrm{L}$. We use a solution containing bicarbonate concentration of $32-35 \mathrm{mEq} / \mathrm{L}$ in all patients, except those who are treated with regional citrate anticoagulation.

\section{Phosphate}

Standard solutions contain either no phosphorus or $1 \mathrm{mmol} / \mathrm{L}$ phosphorus. We use phosphorus-containing solution in patients with the serum phosphate $<4.5 \mathrm{mg} / \mathrm{dL}$ and phosphorus-free solution in all other patients.

\section{Glucose}

Standard solutions either are glucose free or contain between 100 and $110 \mathrm{mg} / \mathrm{dL}$ glucose. We use a solution with $100 \mathrm{mg} / \mathrm{dL}$ of glucose. Some clinicians have suggested using glucose-free solutions in order to improve glucose control among hyperglycemic patients. However, this has not been evaluated in a systematic fashion, and there is a theoretical risk of hypoglycemia with glucosefree solutions.

\section{Calcium}

Standard solutions are calcium free or contain $2.5-3.5 \mathrm{mEq} / \mathrm{L}$ calcium. We use calcium-free solution if citrate is used. We use a maximum calcium concentration of $2.5 \mathrm{mEq} / \mathrm{L}$ if the solution contains phosphorus.

\section{Net UF}

We use the term net ultrafiltration to denote the net volume of fluid removed from the patient after discounting fluids administered to facilitate the dialysis during various forms of CKRT such as replacement fluids and dialysate. ${ }^{9}$ It is important to note, however, that the rate of $U_{\mathrm{NET}}$ must be prescribed based on patient body weight (e.g., $\mathrm{mL} / \mathrm{kg} / \mathrm{hour}$ ), similar to the prescription of effluent dosing for solute clearance, rather than absolute volumes (e.g., $\mathrm{mL}$ / hour), since the use of absolute volumes are likely to expose patients to variable rates, and non-weight-based UF dosing regimens are associated with higher episodes of intradialytic hypotension. ${ }^{10}$

Emerging evidence from recent observational studies suggests a "J"-shaped association between the rate of UF NET $_{\text {and }}$ anortality among critically ill patients. One study found that UF rates less than $<1.0 \mathrm{~mL} / \mathrm{kg} /$ hour or $<20 \mathrm{~mL} / \mathrm{kg} /$ day were associated with increased mortality. ${ }^{11}$ Another study found that $\mathrm{UF}_{\mathrm{NET}}$ rates greater than 1.75 $\mathrm{mL} / \mathrm{kg} / \mathrm{hour}$ compared with rates less than $1.01 \mathrm{~mL} / \mathrm{kg} / \mathrm{hour}$ were associated with lower survival and higher dialysis dependence (Table 2). ${ }^{12}$ Moderate $U_{\text {NET }}$ rates between 1.01 and $1.75 \mathrm{~mL} / \mathrm{kg} /$ hour appear to be associated with the lowest risk of death. ${ }^{12}$

In general, UF $\mathrm{NET}_{\mathrm{N}}$ should not be commenced during the resuscitation phase in a hemodynamically unstable patient requiring vasopressors. However, $\mathrm{UF}_{\mathrm{NET}}$ may be initiated at a slower rate during the de-resuscitation phase in patients who are on low and stable dose of a vasopressor, with careful monitoring of hemodynamics. We suggest to keep $U_{\mathrm{NET}_{\mathrm{T}}}$ rates low until the safety of higher $U_{\mathrm{NET}}$ rates are confirmed in clinical trials. In some patients, however, such as those with life-threatening and severe left ventricular failure and acute respiratory distress syndrome with fluid overload and refractory hypoxemia, higher $\mathrm{UF}_{\mathrm{NET}}$ rates may need to be used and prioritized over the use of, or increase in the dose of, vasopressors, to prevent sudden death.

\section{Intermittent Hemodialysis}

The dosing for solute clearance during IHD is based upon the dose delivered per session as well as the frequency of treatment sessions. The Veterans Affairs/National Institute of Health Acute Kidney Failure Trial Network (ATN) study conducted in the United

Table 2: Observational studies evaluating the association of net ultrafiltration rate on clinical outcomes in critically ill patients with acute kidney injury

\begin{tabular}{|c|c|c|c|c|}
\hline Author & Study population & Exposure & Control & Key findings \\
\hline Gleeson et al. & $\mathrm{AKI}+\mathrm{CKRT}$ & Higher UFR & Lower UFR & $\uparrow$ Dialysis dependence in survivors \\
\hline Murugan et al. & $\begin{array}{l}\mathrm{AKI}+>5 \% \mathrm{FO}+\mathrm{IHD}+ \\
\mathrm{CVVHDF}\end{array}$ & $>25 \mathrm{~mL} / \mathrm{kg} /$ day & $<20 \mathrm{~mL} / \mathrm{kg} /$ day & $\downarrow 1$-year mortality \\
\hline Pawjeski et al. & AKI survivors & Higher UFR & Lower UFR & $\begin{array}{l}\uparrow \text { Dialysis dependence at } 90 \text { days among } \\
\text { survivors }\end{array}$ \\
\hline Murugan et al. & $\mathrm{AKI}+\mathrm{CVVHDF}$ & $>1.75 \mathrm{~mL} / \mathrm{kg} / \mathrm{hour}$ & $\begin{array}{l}<1.01 \mathrm{~mL} / \mathrm{kg} / \\
\text { hour }\end{array}$ & $\begin{array}{l}\uparrow 90 \text {-day mortality, } \downarrow \text { kidney recovery and } \\
\uparrow \text { risk of dialysis dependence }\end{array}$ \\
\hline Naorungroj et al. & $\mathrm{AKI}+\mathrm{CVVHDF}$ & $>1.75 \mathrm{~mL} / \mathrm{kg} /$ hour & $\begin{array}{l}<1.01 \mathrm{~mL} / \mathrm{kg} / \\
\text { hour }\end{array}$ & $\uparrow 28$-day hospital mortality \\
\hline
\end{tabular}

HD, hemodialysis; AKI, acute kidney injury; CKRT, continuous kidney replacement therapy; CVVHDF, continuous venovenous hemodiafiltration; FO, fluid overload; UFR, ultrafiltration rate 
States evaluated intensive dosing strategy vs less intensive dosing strategy in 1,124 critically ill patients treated with IHD, CKRT, or PIKRT based on the hemodynamic status. ${ }^{4}$ Among patients randomized to intensive dosing strategy, IHD and PIKRT were given six times per week with a target $K t / V$ of 1.2-1.4 per treatment, while CKRT was provided with an effluent flow rate of $35 \mathrm{~mL} / \mathrm{kg} /$ hour. Among patients randomized to less intensive strategy, IHD and PIKRT were provided three times per week with target $K t / V$ of 1.2-1.4 per treatment, while CKRT was provided with an effluent flow rate of $20 \mathrm{~mL} / \mathrm{kg} /$ hour. Both the 60 -day mortality rate and dialysis dependence rates were similar. However, the group that received intensive therapy had increased number of episodes of hypotension. Thus, more intensive kidney support beyond that obtained with a standard thrice-weekly regimen (target $\mathrm{Kt} / \mathrm{V}$ of 1.2-1.4 per treatment) or standard CKRT (effluent flow rate of 20 $\mathrm{mL} / \mathrm{kg}$ per hour) does not improve clinical outcomes.

\section{Dialysate Composition}

The dialysate solution composition consists of potassium, sodium, bicarbonate (or other buffer), calcium, magnesium, chloride, and glucose.

\section{Potassium}

If the predialysis serum potassium level is $<4.5 \mathrm{mEq} / \mathrm{L}$, we suggest using a dialysate potassium concentration of $4 \mathrm{mEq} / \mathrm{L}$ to prevent hypokalemia. If the predialysis serum potassium level is between 4.5 and $5.5 \mathrm{mEq} / \mathrm{L}$, we use a dialysate potassium of $3 \mathrm{mEq} / \mathrm{L}$. However, if the patient has an ongoing reason for hyperkalemia (e.g., rhabdomyolysis), we use a lower dialysate potassium of $2 \mathrm{mEq} / \mathrm{L}$. For patients at increased risk of arrhythmias, avoid using a dialysate potassium $<3 \mathrm{mEq} / \mathrm{L}$. Patients who have ongoing risks of hyperkalemia and are at risk of arrhythmias may benefit from CKRT.

For most patients with a potassium level between $5.5 \mathrm{mEq} / \mathrm{L}$ and $8 \mathrm{mEq} / \mathrm{L}$, we use a $2 \mathrm{mEq} / \mathrm{L}$ dialysate potassium bath. For patients with severe hyperkalemia (e.g., $>8 \mathrm{mEq} / \mathrm{L}$ ), we use a dialysate potassium concentration of $1 \mathrm{mEq} / \mathrm{L}$ in order to rapidly decrease the serum potassium to a safer level. All patients who are being dialyzed with a dialysate potassium concentration of $1 \mathrm{mEq} / \mathrm{L}$ should be monitored for arrhythmias, and we check the serum potassium every 30-60 minutes during dialysis. Once the serum potassium is between $6 \mathrm{mEq} / \mathrm{L}$ and $7 \mathrm{mEq} / \mathrm{L}$, the dialysate potassium concentration can be changed to $2 \mathrm{mEq} / \mathrm{L}$ for the remainder of the hemodialysis session.

\section{Sodium}

For patients with normal or near-normal serum sodium levels, we use a dialysate sodium concentration of $137 \mathrm{mEq} / \mathrm{L}$. Among patients with severe chronic hyponatremia (i.e., $<120 \mathrm{mEq} / \mathrm{L}$ ), we set the dialysate sodium to the lowest commercially available setting (130 $\mathrm{mEq} / \mathrm{L}$ ), reduce the blood flow rate to $2 \mathrm{~mL} / \mathrm{kg} /$ minute, and reduce the dialysis time. If the serum sodium concentration is only mildly elevated, we use a dialysate sodium concentration that is within 2 $\mathrm{mEq} / \mathrm{L}$ of the plasma sodium concentration. The use of dialysate sodium concentrations more than 3-5 $\mathrm{mEq} / \mathrm{L}$ below the plasma sodium concentration is associated with hypotension, muscle cramps, and disequilibrium syndrome. Rapid correction of severe chronic hypernatremia should be avoided as overcorrection may lead to cerebral edema. Patients with extremely high serum sodium concentrations are best treated with CKRT.

\section{Buffer Solutions}

For patients with mild or moderate metabolic acidosis (i.e., serum bicarbonate 10-23 mEq/L) or with no acid-base disorder, we generally use a standard dialysate bicarbonate concentration of approximately $3035 \mathrm{mEq} / \mathrm{L}$. For patients with severe metabolic acidosis (i.e., serum bicarbonate $<10 \mathrm{mEq} / \mathrm{L}$ ), we use a dialysate bicarbonate solution of approximately $3540 \mathrm{mEq} / \mathrm{L}$. For such patients, an extended duration of hemodialysis may be necessary.

For patients with alkalosis, the clinician should investigate whether there is ongoing generation vs a one-time insult causing the alkalosis. A one-time insult can be resolved with a single hemodialysis treatment, whereas ongoing generation of alkalosis may require frequent and/or long hemodialysis sessions with a lower bicarbonate dialysate. Both the blood $\mathrm{pH}$ and serum bicarbonate should be determined to appropriately assess the degree of alkalosis. If the serum bicarbonate level is $>28 \mathrm{mEq} / \mathrm{L}$ or respiratory alkalosis is present, we use a bicarbonate concentration of 25-30 mEq/L. We do not use a dialysate bicarbonate of lower than $25 \mathrm{mEq} / \mathrm{L}$.

\section{Calcium}

The dialysate calcium ranges from 2 to $3.5 \mathrm{mEq} / \mathrm{L}$ and is adjusted based on the serum calcium. The major concern in acute hemodialysis is that lower calcium concentration bath may prolong and increase the variability of the QTc interval, both risk factors for sudden death. For patients with mild hypocalcemia, normocalcemia, or mild hypercalcemia [total plasma calcium level was between 8 and $12 \mathrm{mg} / \mathrm{dL}$ ( 2 to $3 \mathrm{mmol} / \mathrm{L}$, corrected for hypoalbuminemia)], we use a dialysate calcium concentration of $2.5 \mathrm{mEq} / \mathrm{L}$. For patients with significant hypocalcemia [total plasma calcium level $<8 \mathrm{mg} / \mathrm{dL}(<2 \mathrm{mmol} / \mathrm{L})$, corrected for hypoalbuminemia], particularly if the patient is symptomatic, we use a dialysate calcium concentration of 3 to $3.5 \mathrm{mEq} / \mathrm{L}$. For patients with severe hypercalcemia [total plasma calcium level $>12 \mathrm{mg} / \mathrm{dL}$ (>3 mmol/L) corrected for hypoalbuminemia], we use a dialysate calcium concentration of $2-2.5 \mathrm{mEq} / \mathrm{L}$.

\section{Magnesium}

The usual dialysate magnesium concentration is $0.5-1 \mathrm{mEq} / \mathrm{L}$. Either concentration will address hypermagnesemia. Hypomagnesemia is usually corrected with IV or oral supplementation.

\section{Blood Flow Rate}

For the first dialysis session, we select the blood flow rate based on the degree of azotemia prior to starting dialysis. If BUN is $>100 \mathrm{mg} /$ $\mathrm{dL}$, we use a blood flow rate of $200 \mathrm{~mL} /$ minute for the first treatment or two (of 2-2.5 hours each). We gradually increase the blood flow and treatment time over several consecutive days. Among patients with severe azotemia, the rapid reduction of BUN and plasma osmolarity should be avoided in order to prevent dialysis syndrome. In addition, for severely azotemic patients, CKRT may be performed.

\section{Ultrafiltration}

Several observational studies conducted among patients with the end-stage kidney disease treated with IHD have also found that higher UF rates are associated with increased mortality. ${ }^{13-17}$ Based on these studies, the Centers for Medicare and Medicaid Services in the United States have proposed that UF rates should be limited to less than $13 \mathrm{~mL} / \mathrm{kg} /$ hour among patients with the end-stage 
kidney disease treated with hemodialysis. ${ }^{18}$ Based on these studies, we suggest using a UF rate of less than $13 \mathrm{~mL} / \mathrm{kg} / \mathrm{hour}$ for patient treated with IHD until further evidence from randomized trials confirms the safety and efficacy of higher UF rates in critically ill patients treated with IHD.

Ultrafiltration during hemodialysis can result in significant intradialytic hypotension. This can be treated by reducing or discontinuing UF. In addition, measures that help prevent intradialytic hypotension include increasing the frequency and/ or duration of treatments, cooling dialysate temperature to $36^{\circ} \mathrm{C}$, sodium and UF profiling in which the sodium and UF rates are varied during the dialysis; and higher dialysate calcium concentration. Any or all of these suggestions may be necessary in any given hemodialysis treatment. However, there is very little evidence for the safety of these approaches in critically ill patients.

\section{Conclusion}

In summary, solute dosing and volume dosing in critically ill patients with AKI depend on the modality of KRT. Evidence from high-quality clinical trials suggests that a minimum effluent dose of $25 \mathrm{~mL} / \mathrm{kg} /$ hour per day using CKRT and a $K t / V$ of 1.3 per session of dialysis using IHD provides optimal solute dosing. However, the dosing for volume mostly depends on the patient's hemodynamic status. Emerging observational studies suggest that higher UF $\mathrm{NET}_{\mathrm{NET}}$ rates are associated with poor outcomes compared with moderate $\mathrm{UF}_{\mathrm{NET}}$ rates. Until the safety of higher $\mathrm{UF}_{\mathrm{NET}}$ is established using randomized trials, we suggest modest $U F_{N E T}$ rates during $K R T$, and volume dosing should be based on patient weight.

\section{References}

1. Kidney Disease: Improving Global Outcomes (KDIGO). Clinical practice guideline for acute kidney injury. Kidney Int Suppl 2012;2(1):1-138. DOI: 10.1038/kisup.2012.1.

2. Clark WR, Ronco C. Renal replacement therapy in acute renal failure: solute removal mechanisms and dose quantification. Kidney Int Suppl 1998;66:S133-S137.

3. RENAL RRT Investigators. Intensity of continuous renal-replacement therapy in critically ill patients. N Engl J Med 2009;361(17):1627-1638. DOI: 10.1056/NEJMoa0902413.

4. Acute renal failure Trial Network (ATN) Investigators. Intensity of renal support in critically ill patients with acute kidney injury. N Engl J Med 2008;359(1):7-20. DOI: 10.1056/NEJMoa0802639.

5. Venkataraman R, Kellum JA, Palevsky P. Dosing patterns for continuous renal replacement therapy at a large academic medical center in the United States. J Crit Care 2002;17(4):246-250. DOI: 10.1053/jcrc.2002.36757.
6. Vesconi S, Cruz DN, Fumagalli R, Kindgen-Milles D, Monti G, Marinho $A$, et al. Delivered dose of renal replacement therapy and mortality in critically ill patients with acute kidney injury. Crit Care 2009;13(2):R57. DOI: 10.1186/cc7784.

7. Bagshaw SM, Chakravarthi MR, Ricci Z, Tolwani A, Neri M, De Rosa $\mathrm{S}$, et al. Precision continuous renal replacement therapy and solute control. Blood Purif 2016;42(3):238-247. DOI: 10.1159/000448507.

8. Friedrich JO, Wald R, Bagshaw SM, Burns KE, Adhikari NK. Hemofiltration compared to hemodialysis for acute kidney injury: systematic review and meta-analysis. Crit Care 2012;16(4):R146. DOI: 10.1186/cc11458.

9. Neri M, Villa G, Garzotto F, Bagshaw S, Bellomo R, Cerda J, et al. Nomenclature for renal replacement therapy in acute kidney injury: basic principles. Crit Care 2016;20(1):318. DOI: 10.1186/s13054-016-1489-9.

10. Pirkle JL, Comeau ME, Langefeld CD, Russell GB, Balderston SS, Freedman $\mathrm{Bl}$, et al. Effects of weight-based ultrafiltration rate limits on intradialytic hypotension in hemodialysis. Hemodial Int 2018;22:(2):270-278. DOI: 10.1111/hdi.12578.

11. Murugan R, Balakumar V, Kerti SJ, Priyanka P, Chang CCH, Clermont G, et al. Net ultrafiltration intensity and mortality in critically ill patients with fluid overload. Crit Care 2018;22(1):223. DOI: 10.1186/s13054-018-2163-1.

12. Murugan R, Kerti SJ, Chang C-CH, Gallagher M, Clermont G, Palevsky $\mathrm{PM}$, et al. Association of net ultrafiltration rate with mortality among critically ill adults with acute kidney injury receiving continuous venovenous hemodiafiltration: A secondary analysis of the randomized evaluation of normal vs augmented level (RENAL) of renal replacement therapy trial. JAMA Netw Open 2019;2(6):e195418. DOI: 10.1001/jamanetworkopen.2019.5418.

13. Flythe JE, Curhan GC, Brunelli SM. Shorter length dialysis sessions are associated with increased mortality, independent of body weight. Kidney Int 2013;83(1):104-113. DOI: 10.1038/ki.2012.346.

14. Flythe JE, Kimmel SE, Brunelli SM. Rapid fluid removal during dialysis is associated with cardiovascular morbidity and mortality. Kidney Int 2011;79(2):250-257. DOI: 10.1038/ki.2010.383.

15. Kim TW, Chang TI, Kim TH, Chou JA, Soohoo M, Ravel VA, et al. Association of ultrafiltration rate with mortality in incident hemodialysis patients. Nephron 2018;139(1):13-22. DOI: 10.1159/ 000486323.

16. Movilli E, Gaggia P, Zubani R, Camerini C, Vizzardi V, Parrinello $G$, et al. Association between high ultrafiltration rates and mortality in uraemic patients on regular haemodialysis. A 5-year prospective observational multicentre study. Nephrol Dial Transplant 2007;22(12):3547-3552. DOI: 10.1093/ndt/gfm466.

17. Saran R, Bragg-Gresham JL, Levin NW, Twardowski ZJ, Wizemann $V$, Saito $A$, et al. Longer treatment time and slower ultrafiltration in hemodialysis: associations with reduced mortality in the DOPPS. Kidney Int 2006;69(7):1222-1228. DOI: 10.1038/sj.ki.5000186.

18. Kramer H, Yee J, Weiner DE, Bansal V, Choi MJ, Brereton L, et al. Ultrafiltration rate thresholds in maintenance hemodialysis: an NKFKDOQI controversies report. Am J Kidney Dis 2016;68(4):522-532. DOI: 10.1053/j.ajkd.2016.06.010. 